\title{
APLIKASI UNTUK MENYEMBUNYIKAN FILE PADA HANDPHONE MENGGUNAKAN JAVAME
}

\author{
Novrido Charibaldi, Hajad Adhy Putra \\ Jurusan Teknik Informatika UPN "Veteran" Yogyakarta \\ Jl.Babarsari no 2 Tambakbayan 55281 Yogyakarta \\ email: novrido@gmail.com
}

\begin{abstract}
Mobile is now not only as a means to communicate, recently mobile technology / mobile phone, the more feture like java platform provided therein. The latest mobile phones are now equipped with a MMC (MultiMediaCard), which are mostly used to store data in the form of text, image (the images), sound, video clips and scripts. This application is expected to hide the confidentiality of critical data and personal data on a mobile phone. The method used in the design and manufacture of this software is a method Grapple (Guidlines for Rappid Application Engineering), NetBeans IDE 6.0 is used as a tool to help programming. System modeling language used is the Unified Modeling Language (UML). The programming language used was JavaME
\end{abstract}

Keyword: Handphone, JavaME, File, NetBeans IDE 6.0, GRAPPLE, UML.

Handphone sekarang bukan hanya sebagai alat untuk berkomunikasi, belakangan ini teknologi mobile / handphone, semakin banyak feture yang diberikan seperti java platform di dalamnya. Handphone keluaran terbaru kini di lengkapi dengan MMC (MultiMediaCard), yang kebanyakan digunakan untuk menyimpan data berupa text, image (hasil foto), suara, video clip maupun script. Aplikasi ini diharapkan dapat menyembunyikan kerahasiaan data penting maupun data yang bersifat pribadi pada sebuah handphone. Metode yang digunakan dalam perancangan dan pembuatan perangkat lunak ini adalah metode GRAPPLE (Guidlines for Rappid APPLication Engineering), NetBeans IDE 6.0 digunakan sebagai tools untuk membantu pemrograman. Bahasa pemodelan sistem yang digunakan adalah Unified Modelling Language (UML). Bahasa pemrograman yang digunakan adalah JavaME

Kata kunci : Handphone, JavaME, File, NetBeans IDE 6.0, GRAPPLE, UML.

\section{PENDAHULUAN}

Handphone selain sebagai alat komunikasi sekarang juga dapat digunakan untuk menyimpan data baik di dalam memori handphone maupun di dalam MMC. Banyaknya pengguna handphone mulai mengeluh akan keamanan data pada handphone-nya, yang dapat dengan mudah berpindah tangan kepada orang lain yang tidak berhak (anauthorized person).

Dalam aplikasi ini mengacu pada system yang terdapat dalam windows dimana pengguna dapat menyembunyikan file yang di rasanya tidak perlu diketahui oleh orang lain atau yang bersifat pribadi. Dalam sebuah personal computer istilah hidden sudah tidak terdengar asing lagi, di karenakan sudah banyak pengguna personal computer dengan sengaja menyembunyikan file atau data dengan menggunakan cara hidden. Dalam penelitian ini akan dibuat aplikasi untuk menyembunyikan file pada handphone menggunakan javame yang mempermudah pengguna handphone dalam melindungi data atau file yang dimilikinya.

Tujuan penelitian ini adalah menghasilkan aplikasi yang dapat menyembunyikan file dalam handphone dengan memanfaatkan teknologi java didalamnya. Aplikasi ini lebih dikhususkan untuk handphone yang memiliki fiture java.

Manfaat yang diharapkan dari penulisan skripsi ini adalah mengurangi resiko pengguna handphone mengalami pengambilan data dan mempermudah pengguna handphone dalam menjaga kerahasiaan data yang berada dalam handphone-nya.

\section{TINJAUAN PUSTAKA}

Metodologi yang digunakan untuk membuat permainan ini adalah Guidelines for Rapid APPLication Engineering atau biasa disebut GRAPPLE yang terdiri dari lima segment yaitu 
Requirement gathering (perencanaan kebutuhan), Analysis (analisis), Design (perancangan), Development (pengembangan), Deployment (penyebaran).

Penelitian ini mengacu pada penelitian Tri Prasetyo dengan NIM 12300017 pada tahun 2008 dengan judul aplikasi enkripsi/deskripsi pada handphone menggunakan metode enkripsi AES(RIJNDAEL) Universitas Pembangunan Nasional "Veteran" Yogyakarta.

Perbedaan dari penelitian yang dilakukan oleh Tri Prassetyo yaitu dalam implementasi dan penerapan aplikasi. Pada aplikasi enkripsi/deskripsi pada handphone menggunakan metode enkripsi AES(RIJNDAEL) pengamanan yang dilakukan untuk sebuah pesan SMS atau text. Sedangkan aplikasi yang penulis buat dapat mengamankan beberapa jenis file seperti Audio, Video(clips), Image, dan Text dengan cara menyembunyikan file sehingga tidak dapat dibaca oleh orang lain yang tidak berhak mengakses file tersebut. Metodologi yang digunakan dalam membangun aplikasi enkripsi/deskripsi pada handphone menggunakan metode enkripsi AES(RIJNDAEL) adalah RUP/UP (Rational Unified Proccess/Unified Proccess) Sedangkan dalam aplikasi ini, metodologi pengembangan system yang digunakan adalah GRAPPLE.

\section{METODELOGI PENELITIAN}

Metode yang digunakan adalah GRAPPLE (Guidlines for Rappid APPLication Engineering), yang tujuan untuk menghasilkan sistem berorientasi objek dalam waktu yang singkat tanpa mengurangi kualitas sistem yang dibangun (Schmuller, 1999). GRAPPLE merupakan sebuah pemodelan proses dalam pengembangan software yang menekankan pada aksi-aksi yang dilakukan pada sejumlah tahapan, setiap tahap akan menghasilkan produk kerja dengan bentuk yang berorientasi objek (Schmuller, 1999).

Dalam GRAPPLE, tahapan dapat disusun dalam bentuk yang tidak statis, sehingga setiap tahap dapat dikerjakan dengan urutan kerja yang tidak harus sesuai dengan urutan yang ada. Tahapan yang digunakan dalam GRAPPLE mencakup analisis kebutuhan sistem, pengembangan model dan diagram, pembuatan code sampai tahap instalasi dan evaluasi.

1. Requirements Gathering

Tahap ini melakukan analisis terhadap masalah, fungsi dan komponen produk yang akan dibuat (system requirements). Tahap ini penting, karena tahap lain tidak dapat dibuat sesuai dengan yang diinginkan jika tidak memahami produk yang akan dibuat.

2. Analysis

Tahap pengembangan model dari data dan informasi yang diperoleh dari requiremens gathering. Model merupakan bentuk transisi dari informasi dasar kedalam bentuk model dan diagram.

3. Design

Merupakan tahap implementasi dan perancangan dari model serta diagram yang telah dianalisis. Dalam tahap ini akan dikembangkan sejumlah objek diagram dengan fungsi, interaksi dan operasi tertentu. Diagram-diagram tersebut antara lain akan menunjukkan proses dan aktifitas pada sistem, rancangan data dan penyimpanan data, serta rancangan antarmuka.

4. Development

Merupakan tahap penerapan model dan diagram yang telah terbentuk, antara lain dengan melakukan pengembangan source code, pengecekan dan test code, serta pembuatan User Interface.

5. Deployment

Merupakan tahap terakhir yang dilakukan setelah development. Sistem yang terbentuk akan integrasikan dengan hardware maupun dengan sistem operasi yang digunakan.

\section{METODE REKAYASA PERANGKAT LUNAK}

Pada penelitian ini menggunakan diagram-diagram UML.

\subsection{Diagram High Level Class}

Dari permasalahan yang ada, terdapat enam class yang akan dikembangkan dalam tahapan selanjutnya, yang terdiri dari sebuah Controller Class dan lima buah Boundary Class. Didalam class SecurityFile terdapat lima buah extends thread Login, Hidden, search, SetPassword, dan ChangePassword. 


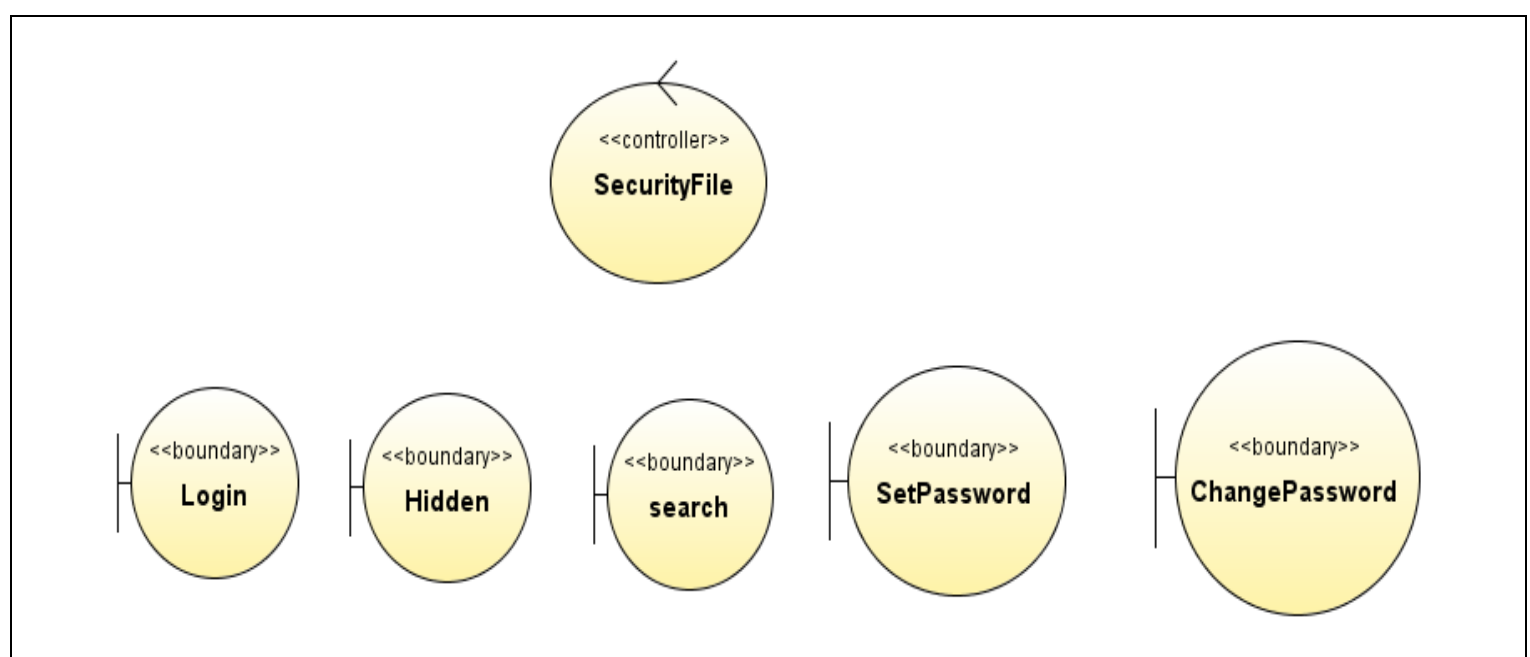

Gambar 1. Diagram High Level Class aplikasi untuk menyembunyikan

\subsection{Diagram Use Case} file pada handphone menggunakan javame.

Diagram Use case terdapat satu actor yaitu pengguna yang dapat berlaku sebagai client atau pun server. Sebagai server pengguna akan berinteraksi dengan empat Use case dalam aplikasi ini yaitu membuat permainan baru, melihat petunjuk permainan, melihat tentang program, keluar aplikasi.

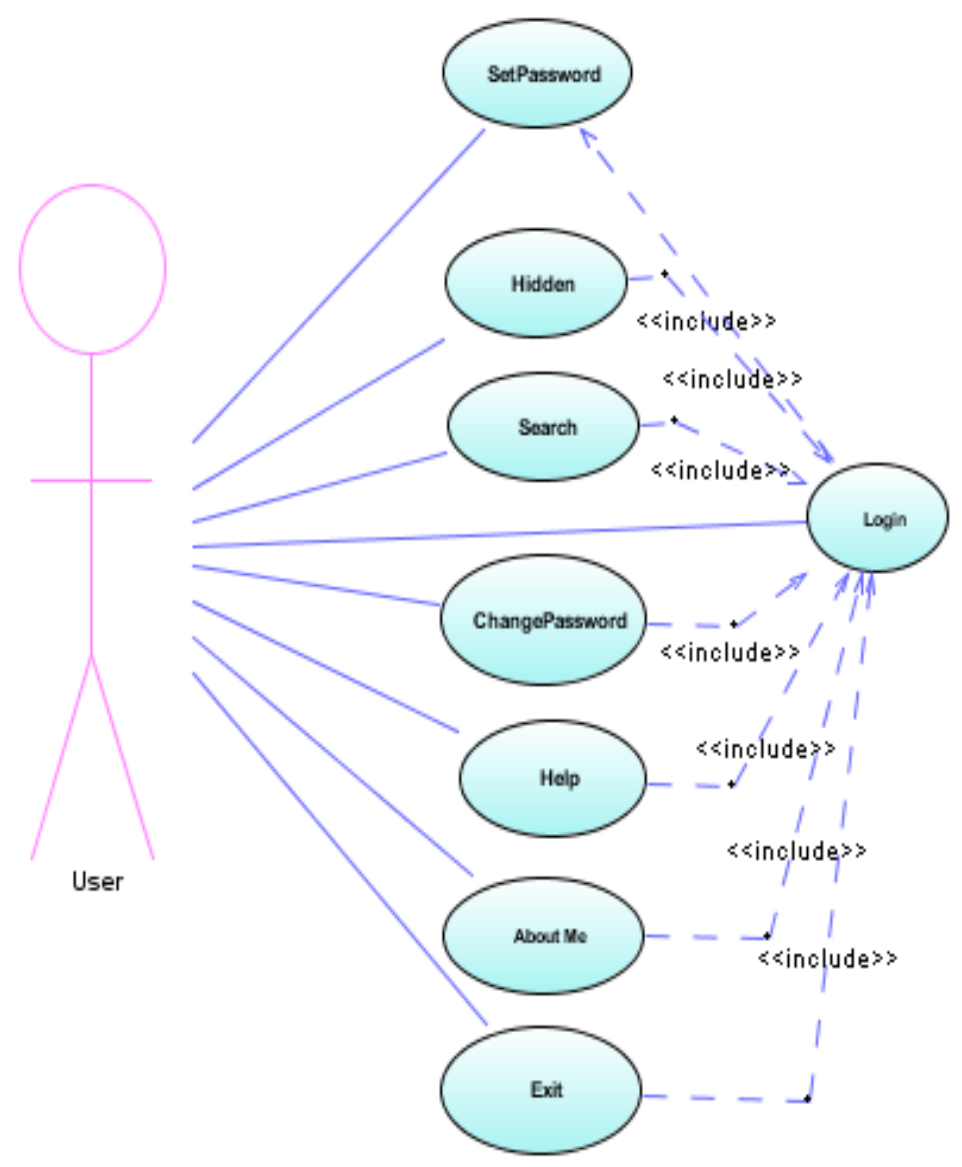

Gambar 2. Diagram Use Case aplikasi untuk menyembunyikan file pada handphone menggunakan javame. 
4.3 Diagram Class

Diagram class pada aplikasi file security pada handphone menggunakan JavaME dibuat menggunakan reverse engineering yang terdapat pada Netbeans 6.0. Terdapat enam buah class. Diagram class ini menunjukan hubungan antara beberapa class. Terdapat enam class dalam aplikasi ini, yaitu class SecurityFile sebagai class utama, class SetPassword yang berfungsi untuk menangani proses membuat password user pada awal masuk aplikasi, class Login yang berfungsi untuk menangani proses login user, class ChangePassword yang berfungsi untuk mengganti password yang lama dengan yang baru, class Hidden yang berfungsi untuk menyembunyikan file, class Search berfungsi untuk melakukkan pencarian file hidden berdasar nama file yang di inputkan pada textfield untuk di ubah menjadi file normal .

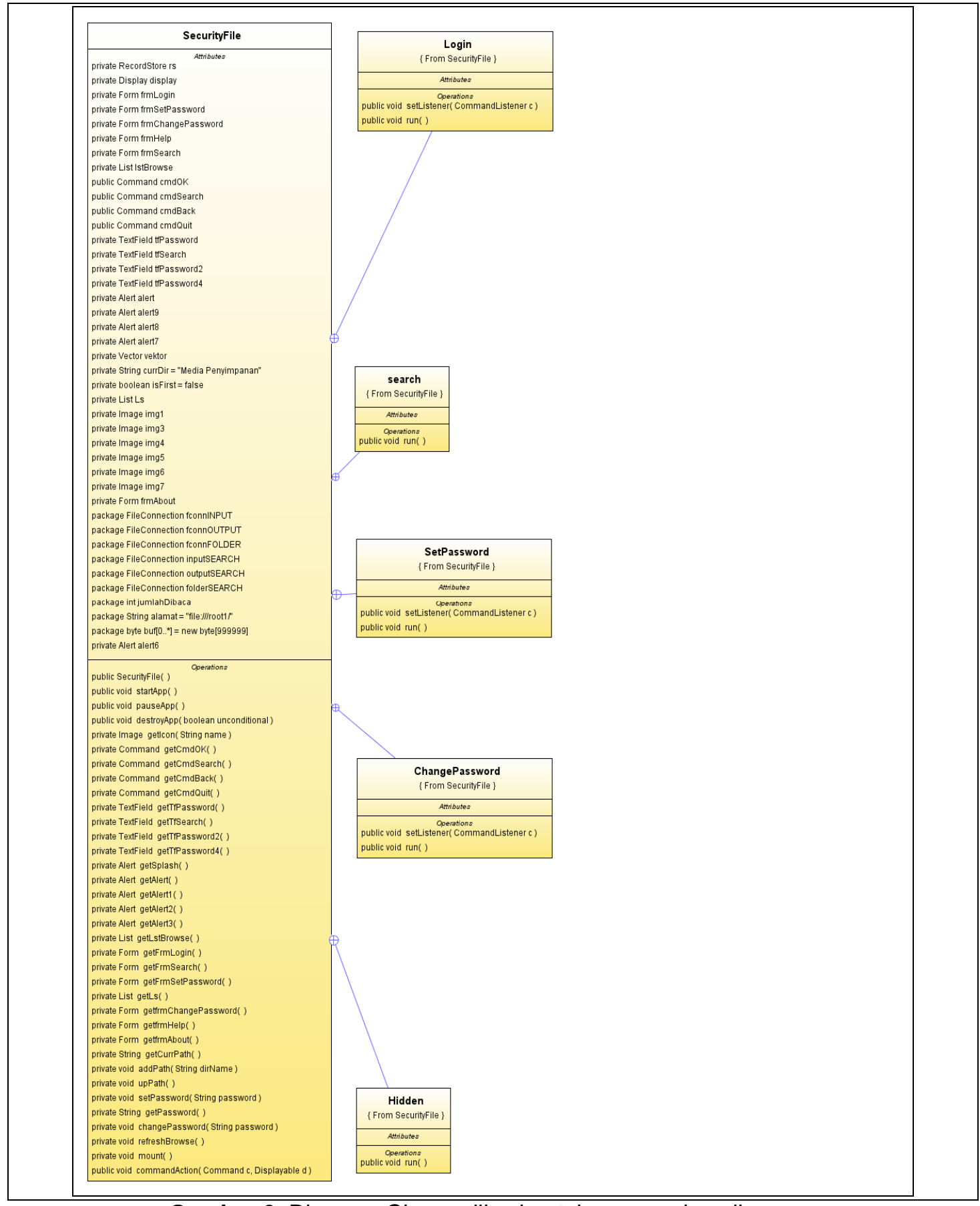

Gambar 3. Diagram Class aplikasi untuk menyembunyikan file pada handphone menggunakan javame. 
4.4 Diagram Sequence

Pada aplikasi untuk menyembunyikan file pada handphone menggunakan javame terdapat beberapa diagram sequence.

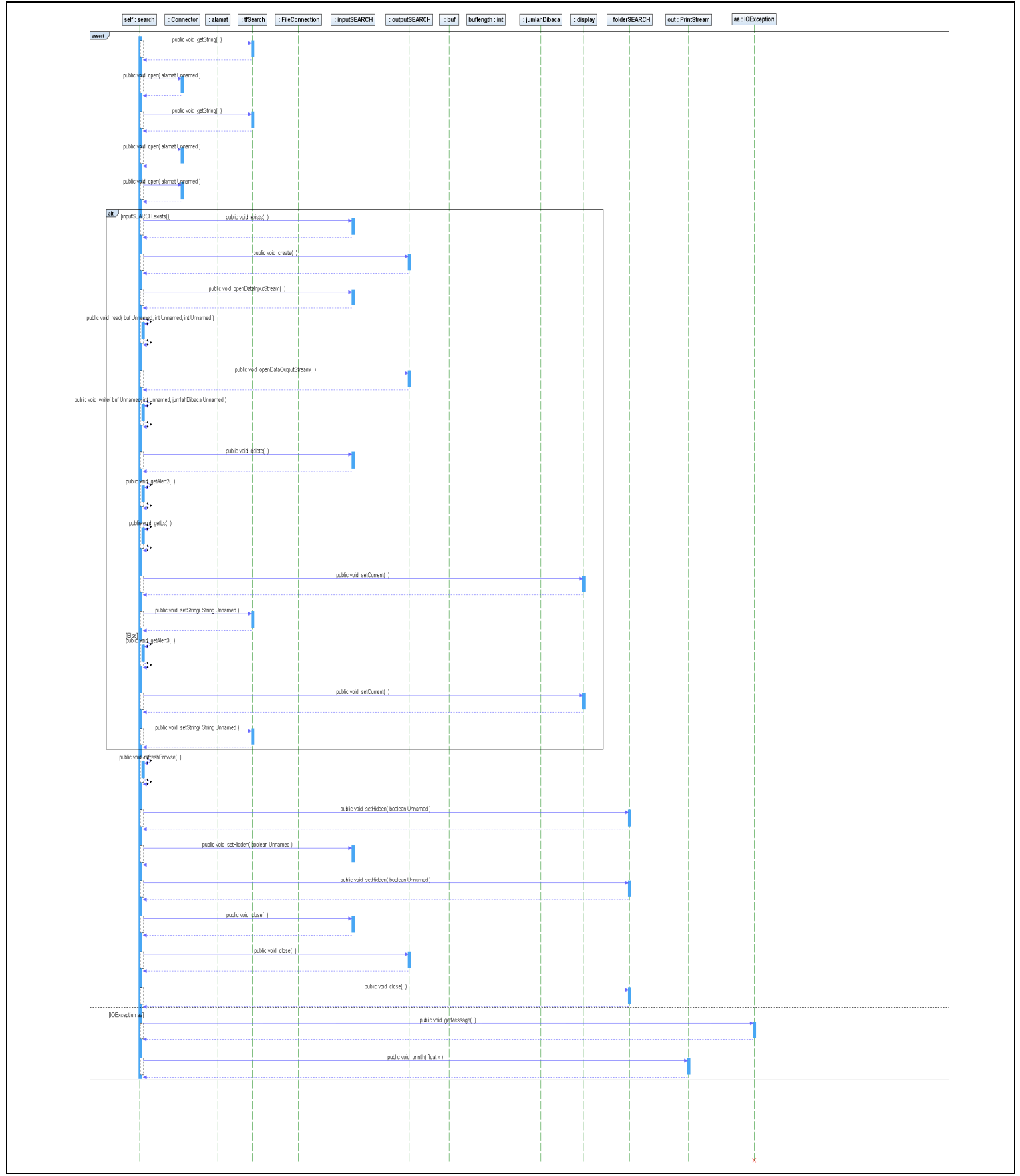

Gambar 4. Diagram Sequence search aplikasi untuk menyembunyikan file pada handphone menggunakan javame. 
4.5 Diagram StateChart

Statechart diagram menggambarkan perilaku dinamis suatu objek dan memuat informasiinformasi tentang berbagai state saat suatu objek ada, bagaimana transisi suatu state ke state lainnya, serta bagaimana objek berperilaku secara berbeda dalam masing-masing state.

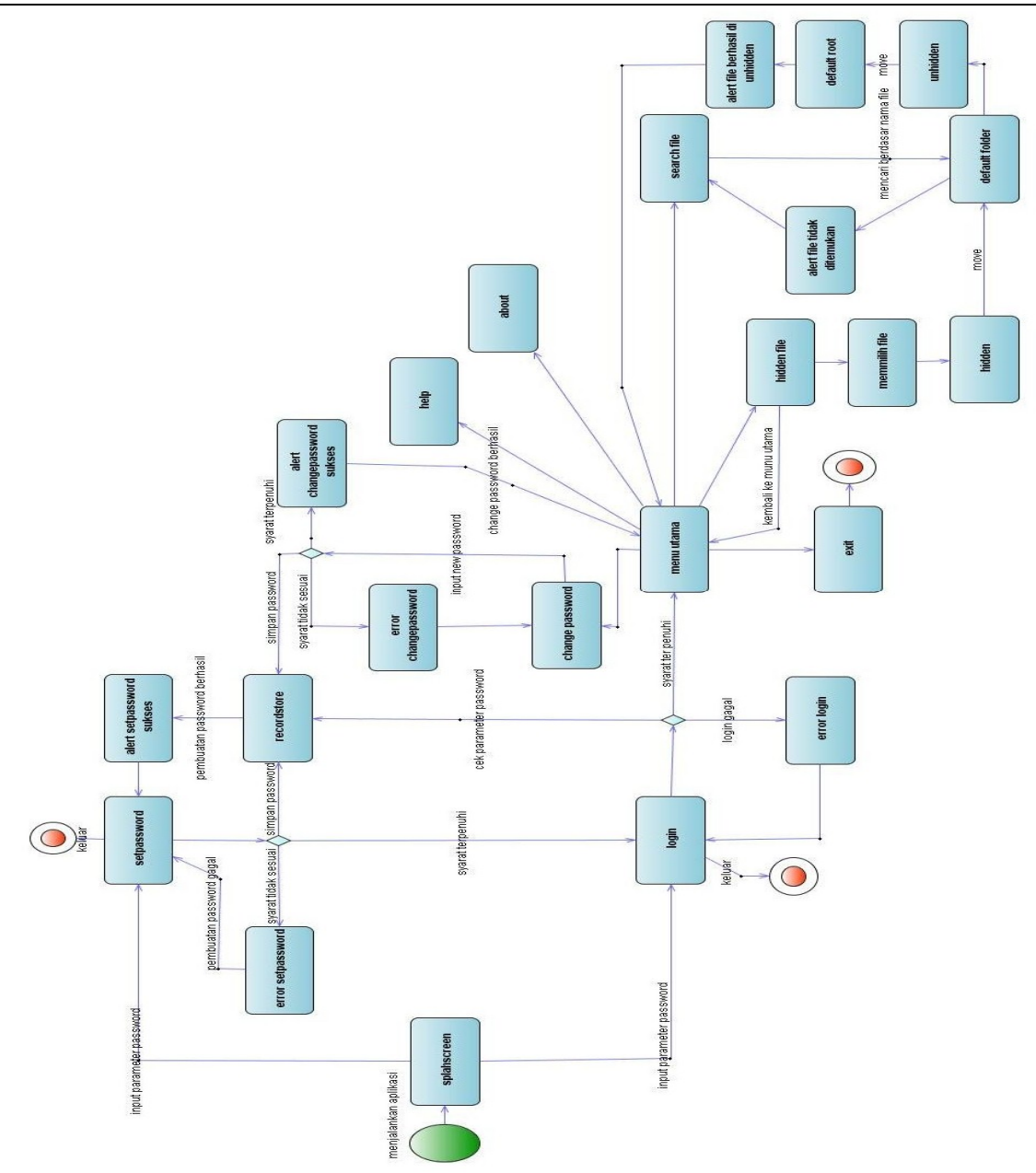

Gambar 5. Diagram StateChart aplikasi untuk menyembunyikan file pada handphone menggunakan javame.

\subsection{Diagram Dependencies}

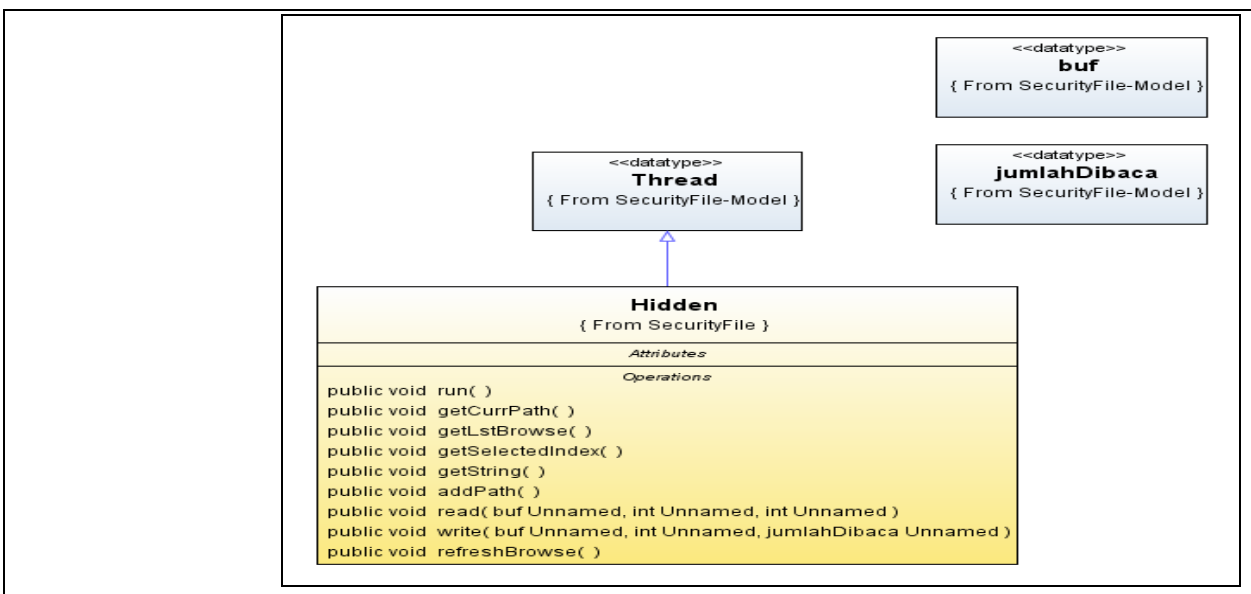

Gambar 6. Diagram Dependencies Hidden aplikasi untuk menyembunyikan file pada handphone menggunakan javame. 


\section{HASIL DAN PEMBAHASAN}

Pada bagian ini hanya akan dibahas hasil implementasi dari beberapa kelas terpenting yang berperan dalam pembangunan aplikasi pada penelitian ini. Kelas utama pada aplikasi untuk menyembunyikan file pada handphone menggunakan javame adalah class SecurtyFile yang di dalamnya terdapat lima class.

Dua dari lima class tersebut adalah class Hidden dimana class ini berperan penting sebagai class yang di operasikan untuk menyembunyikan file. Berikut cuplikan class Hidden:

class Hidden extends Thread\{

public void run ()\{

try \{

fconnFOLDER = (FileConnection)Connector.open(alamat+"Hidden");

if (!fconnFOLDER.exists ()$)\{$

\} fconnFOLDER.mkdir();

else\{

\}

fconnFOLDER.setHidden(false);

\} catch (Exception h) \{

System.out.println("can't create folder" + h.getMessage()); \}

try \{

fconnINPUT $=$ (FileConnection) Connector.open(getCurrPath ()$+$

getLstBrowse().getString(getLstBrowse().getSelectedlndex()));

if(fconnINPUT.isDirectory ()$)\{$

addPath(getLstBrowse().getString(getLstBrowse().getSelectedlndex()));

\} else \{

try \{

fconnFOLDER.setHidden(false);

fconnOUTPUT

(FileConnection)Connector.open(alamat+"Hidden/"+fconnINPUT.getName());

\} catch (IOException a) \{

System.out.printIn("file can't found"+a.getMessage()); \}

if (!fconnOUTPUT.exists ()$)\{$

fconnOUTPUT.create();

jumlahDibaca $=$ fconnINPUT.openDatalnputStream().read(buf, 0, buf.length);

fconnOUTPUT.openDataOutputStream().write(buf, 0,jumlahDibaca);

fconnOUTPUT.setHidden(true);

fconnINPUT.delete();

fconnFOLDER.setHidden(true);

\section{Modul Program 1. class Hidden extend Thread}

Berikut adalah tampilan saat user hendak menyembunyikan file

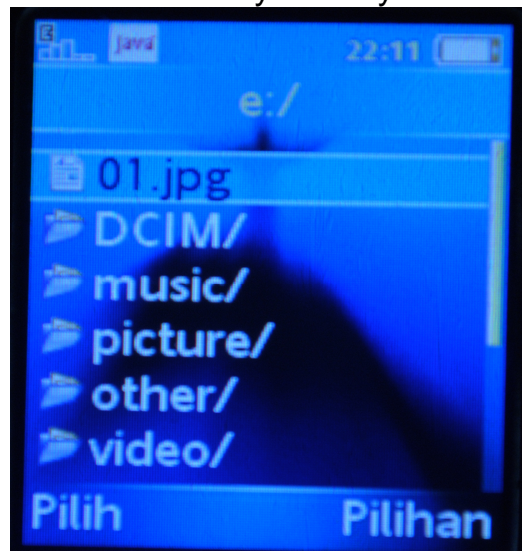

Gambar 7. aplikasi saat user akan menyembunyikan file pada aplikasi untuk menyembunyikan file pada handphone menggunakan javame. 


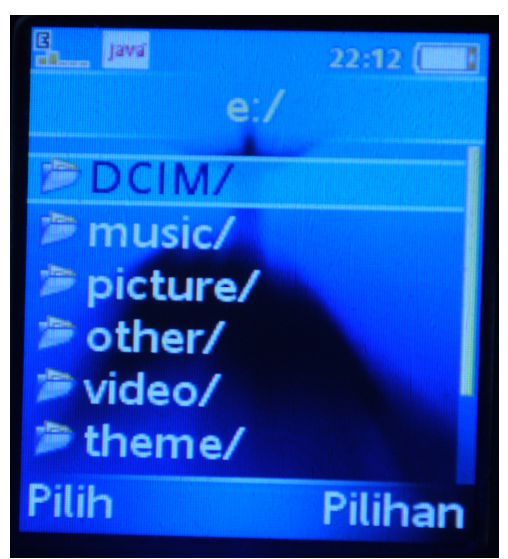

Gambar 8. aplikasi saat user setelah menyembunyikan file pada aplikasi untuk menyembunyikan file pada handphone menggunakan javame.

\section{KESIMPULAN}

Dari semua tahap yang telah dilakukan maka dapat disimpulkan bahwa telah berhasil dibangun aplkasi untuk menyembunyikan file pada handphone, yang memiliki kemampuan untuk menyembunyikan berbagai macam jenis file pada sebuah handphone. Dengan berhasilnya aplikasi ini diharap dapat membantu dalam mengurangi masalah berpindahnya data kepada orang yang tidak berhak mengetahui.

\section{DAFTAR PUSTAKA}

Aditya, Antonius, 2003, Tip dan Trik Java 2 Micro Edition Mobile Interface Device Programming, Penerbit PT Elex Media Komputindo, Jakarta.

Hermawan, Benny, 2004, Menguasai Java 2 \& Object Oriented Programming, Penerbit Andi, YogyakartaMunawar, 2005, Pemodelan Visual Dengan UML, Graha IImu, Yogyakarta.

Raharjo Budi, dkk, 2007, Tuntunan Pemrograman Java untuk Handphone, Informatika, Bandung.

Robin Williams, dan Steve Cumming, 1993, Istilah Mutakhir Dunia Komputer, PT. Dinastindo Adi Perkasa Internasional, Jakarta.

Shalahuddin, M., dan A.S., Rosa, 2006, Pemrograman J2ME : Belajar cepat Pemrograman Perangakat Telekomunikasi Mobile, Informatika, Bandung.

Schmuller, Joseph, 1999, Teach Yourself UML in 24 Hours, Sam Publishing, Indianapolis.

Sri Hartati, dkk, 2006, Pemrograman Java Servlet dan JSP dengan NetBeans, Penerbit Andi, Yogyakarta

Wicaksono, Ady, 2002, Pemrograman Aplikasi Wireless dengan Java, Penerbit PT Elex Media Komputindo, Jakarta. 